\title{
Effect of Residential Area on the Physical Activity of 7 Years Old Child in Malaysia
}

\author{
M A R Zainoddin ${ }^{1}$, M R Abdullah ${ }^{2 *}$, A B H M Maliki², Kalfin $^{3}$ and Ira Sumiati ${ }^{4}$
}

\author{
${ }^{1}$ Faculty of Applied Science Social University of Sultan Zainal Abidin, 21300 University of Sultan Zainal Abidin, Gong \\ Badak Campus, Terengganu, Malaysia. \\ ${ }^{2}$ East Coast Environment Research Institute, 21300 University of Sultan Zainal Abidin, Gong Badak Campus, \\ Terengganu, Malaysia. \\ ${ }^{3}$ Doctor Program of Mathematics, Faculty of Mathematics and Natural Sciences, Universities Padjadjaran, Indonesia \\ ${ }^{4}$ Master Program in Mathematics, Faculty of Mathematics and Natural Science, Universities Padjadjaran, Indonesia \\ *Corresponding author.E-mail: razali896@yahoo.com
}

\begin{abstract}
Environmental factors such as residential areas are found to be related to physical activity in children. Physical activity is really related to the level of physical fitness for a person. Physical activity is the body movement created by the skeletal muscle resulting in energy production. This study aims to identify the characteristics of urban and rural areas based on the physical fitness test and to differentiate the effect of residential areas on the physical activity of 7 years old child in Malaysia. A total of 66481 children were randomly selected from primary schools in entire Malaysia with mean weight $( \pm 23.2871)$, height $( \pm 120.3907)$, and age $( \pm 7.4123)$. Based on their school position, a total of 34458 urban children and 32023 rural children. They were tested by physical fitness tests to measure power, flexibility, coordination, and speed. The analysis used in this study was Principal Components Analysis (PCA) and Multivariate Analysis of Variance (MANOVA). After the varimax rotation in PCA, the result showed that both urban and rural areas have the same characteristic, which is the factor loading of power, coordination, and speed greater than 0.6 . The results of the MANOVA test showed a significant difference of $p<0.05$ for all parameters tested. Besides, both groups showed that children from rural areas tend to have better physical activity than children from the urban area. In summary, environmental factors and lifestyle play an important role in deciding physical activity levels among children. Proper planning and implementing health promotion programs, encouraging regular physical activity practice, need to be implemented to fight against sedentary behavior.
\end{abstract}

Keywords: Residential Area, Urban-Rural, Physical Activity

\section{INTRODUCTION}

Physical activity relates to all energy produced by movement and defined as anybody movement generated by skeletal muscles resulting in energy consumption beyond the level of rest [1]. Physical activity can affect individuals' physical and psychological well-being [2]. Technological developments and modernization often impact society's everyday life in terms of an unhealthy lifestyle. For example, technology such as cell phones is a huge necessity for a family today [3]. Most children are already beginning to be exposed to technology like this. In childhood, parents and their environments strongly affect the behaviors and trends of children's behavior. living area differences in areas differentiated by population size can be attributed to differences in eating habits, access to sports facilities and opportunities for physical activity, and much more [4].

Physical fitness is defined by a set of qualities such as stamina, mobility, and power, combined with the capacity to undertake physical activity. Fitness results mainly from patterns of physical activity but also from genetic causes [5]. Regular physical activity or enhanced physical activity affects multiple health conditions and reduces the risk of several chronic diseases. Physical activity usually plays a major role in one's life and is important to children's health. A healthy lifestyle or environment defines the physical activity of an individual. 
During the past 20 years in Malaysia, obesity and rates of non-communicable physical inactivity diseases have risen dramatically [6]. Malaysia was also rated as one of the least physically active countries globally, with over $60 \%$ of mainly sedentary adults. Previous studies found that physical activity provides many benefits to children's physical and mental well-being. Children's physical activity is important for overcoming the clustering of risk factors in cardiovascular disease, bone growth, and development, to improve self-esteem and avoid anxiety and depression [7].

Physical fitness is quite genetically determined, but surrounding conditions may often be severely impacted [8]. The main determinant of fitness performance is good physical activity. Environmental factors may also be correlated with lifestyle and cardiovascular risks and fitness standards. Today, children are also less active in urban areas. Dollman et al., claimed that children are more likely nowadays to perform no physical activity because many of them prefer activities like eating or sleeping, and such activities are their top 10 [9]. In the previous research, it is said children from rural towns and small towns are more active than urban children [10]. It's undeniable that many children in the city do not have a high fitness standard due to technology, living conditions in suburban areas, noise, social issues, public services, etc. However, a variety of research around the world has shown contradictory findings on living (urban and rural) interactions and physical activity between teenagers and children [4]. From the previous study by Yusoff et al., stated that urban children have better motor skill performance than rural children in Selangor, Malaysia [11]. Therefore, this study aims to identify the characteristics of urban and rural areas based on the physical fitness test and to differentiate the effect of residential areas on the physical activity of 7 years old child in Malaysia.

\section{METHODOLOGY}

\subsection{Area of Study}

This study analyzed data on children's physical fitness in Malaysia. The study involved children from Sekolah Kebangsaan (SK), Sekolah Agama (SA), Sekolah Kebangsaan Jenis Cina SJK (C), and Sekolah Kebangsaan Tamil SJK (T). Almost all children were picked by age seven years. These children were categorized by a school zone comprising of urban and rural areas, and multiple population assessments were carried out to assess the varying standards of physical fitness of the children by category.

\subsection{Participants and Testing Procedure}

A total of 34458 urban children and 32023 rural children aged seven years old were selected from all over primary schools in Malaysia. In the urban area, boys are 18925, while in the rural area is 17364; girls in urban areas are 15533 while in the rural area is 14659 . It is measured with individual anthropometric components (weight and height), as well as four motor subscales, namely flexibility, coordination, speed, and power.

\subsubsection{Anthropometric Components}

Weight $(\mathrm{kg})$ and standing height $(\mathrm{cm})$ of the participants is used in anthropometric measurement included in this study. The participants should stand upright on the weight scale and head forward. Participants should not wear heavy clothing and should remove their shoes and caps. Each measurement is calculated in kilograms $(\mathrm{kg})$. For standing height, with the stadiometer, participants need to stand upright and face forward. Participants should not wear a cap or shoes. Every measurement should be in centimeters $(\mathrm{cm})$ measured. All of these details are collected and kept into the form established.

\subsubsection{Motor Components}

In this study, there are four motor subscales were tested which is flexibility, coordination, speed, and power. For flexibility, the test used is the sit and reach test (SAR). The participants will sit in a prone position on the floor. Both sides of the participant's legs should be straight, and the assistant puts his hands on the participant's knees to ensure that the knees do not move during the test. The palm of the hands with the middle fingertips overlapping. Reach out on the measurement scale as slowly as possible. Maintain the maximum reach for 3 seconds. Participants have to take the test three times. The best achievement will be taken into account as a score. The score will not be calculated if the participant's knee moves during the reach test.

For coordination, a hand wall toss test (HWT) is used. The participants must stand up to the markers and be 1 meter from the wall. The ball is tossed by one arm by behaving against the wall and attempting to retrieve the ball by the other arm. And the ball is thrown back to the wall and caught first-hand-this test proceeds for ten trials. The amount of throws caught is recorded.

Next, the 20-meter run test (20MR) to measure the speed. Before the run starts, the participants will stand behind the starting line. The participants would be instructed to proceed to move as rapidly as possible once the whistle is blown. Participants had 20 meters to sprint. Time is recorded as soon as the participants cross the finish line. This test is conducted twice, and the fastest test is registered. 
A standing broad jump test (SBJ) was used to measure the power of the lower limb. The participants must pose that behind the line marked slightly apart with their foot on the surface. With arms swing back and forth, a two-foot launch and landing were used. They were bending the legs rhythmically to about 90 degrees upward. Participants would strive to jump as long as practicable, without slipping backwards with both legs. This test is cancelled if participants make the error to double jump and step on the line before they leap. Three trials were approved and the farthest accepted.

\subsection{Statistical Analysis}

\subsubsection{Preprocessing data}

Data cleaning is a detecting and correction method for corrupted or inaccurate data in record sets, tables, or databases and refers to the identification of missing, erroneous, incorrect, or irrelevant data components and the replacement, modification, or removal of dirty or coarse data. The nearest neighboring method can be used for matrices that have very small amounts of data lost $(\sim 3 \%)$ than the overall data recorded [3]. The nearest neighbor method is used to solve the missing data, where the endpoints of the gaps are used as estimates of all missing values.

\subsubsection{Principal Component Analysis (PCA)}

In this study, the methodology proposed by Matsudo et al., was used to construct multivariate analysis indicators [12]. Principal Component Analysis (PCA) introduced new generalizing indicators. This is important for testing whether the sample size is sufficiently large and suitable for the PCA. PCA is unprecedented and perfect when matrix effects are established. These factors are extracted by the results of PCA. From this analysis, research can determine which components are affected by the two categories of residential areas; urban and rural. Based on the results, the researcher can determine the characteristics of urban and rural physical activities among the child. PCA may be rendered by decomposing the eigenvalue of a data covariance (or correlation) matrix or decaying the sole value of a data matrix, typically after the initial data is normalized. A PCA results are typically addressed with regard to component scores, also called factor scores, and loadings (the weight by which each standard initial variable is multiplied to achieve a component score). The researcher uses the result of the scree plot to determine which dimension has an eigenvalue of more than 1. After that, the researcher uses the factor loadings to determine the component affected by an independent variable. From this analysis, the researcher can determine the characteristic of physical activity for urban and rural children. The principal component (PC) can be disclosed as equation (1) below; where $\mathrm{z}$ is the element tally, a is the element stacking, $\mathrm{x}$ is the gauged approximation of the variable, $i$ is the element number, $j$ is the subject number, and $m$ is the cluster number of variables [13].

$\mathrm{z}_{\mathrm{ij}}=\mathrm{a}_{\mathrm{i} 1} \mathrm{x}_{1}+\mathrm{a}_{\mathrm{i} 2} \mathrm{x}_{2 \mathrm{j}}+\cdots+\mathrm{a}_{\mathrm{im}} \mathrm{x}_{\mathrm{mj}}$

\subsubsection{Multivariate Analysis of Variance (MANOVA)}

MANOVA is a method of multivariate analysis that analyses data involving multiple dependent variables at a time [14]. MANOVA enables the researcher to check the influence of one or more independent variables on two or more dependent variables. A MANOVA analysis produces a p-value to determine whether the null hypothesis can be dismissed. MANOVA is also used to detect variations in the mean values of dependent variables among the various independent variable levels. MANOVA test can also detect variations in correlations between the dependent variables and various rates of the independent variable, as well as to detect differences in average values.

The researcher uses the MANOVA analysis to make a comparison of the effect of the residential area on the physical activity based on the fitness performance test of 7 years old child in Malaysia. Application of Pearson correlations sequences between all dependent variables will use MANOVA to check the assumption that, at least with a reasonable range, the dependent variables would correlate with each other. Furthermore, covariance matrices were checked for homogeneity in the MANOVA.

\section{RESULTS AND DISCUSSION}

The outcomes of this study are expected twice, (1) identify the characteristics of urban and rural areas based on the physical fitness test and (2) to differentiate the effect of residential areas on the physical activity of 7 years old child in Malaysia. Table 1 shows the descriptive statistics of the mean for urban and rural children.

Table 1. Mean Statistics of Urban-Rural Selected Participants

\begin{tabular}{lcc}
\hline Statistical & $\begin{array}{c}\text { Urban } \\
(\mathrm{N}=34458)\end{array}$ & $\begin{array}{c}\text { Rural } \\
(\mathrm{N}=32023)\end{array}$ \\
\hline $\mathrm{Wg}(\mathrm{kg})$ & 23.57 & 22.99 \\
$\mathrm{Hg}(\mathrm{cm})$ & 120.98 & 119.75 \\
$\mathrm{SBJ}(\mathrm{cm})$ & 100.34 & 102.37 \\
SAR $(\mathrm{cm})$ & 26.42 & 26.96 \\
HWT $(\mathrm{no})$ & 5.16 & 5.43 \\
20MR $(\mathrm{sec})$ & 5.03 & 4.96 \\
\hline
\end{tabular}

Note: Wg: Weight, Hg: Height, SBJ: Standing Broad Jump, SAR: Sit and Reach, HWT: Hand Wall Toss, 20MR: 20-meter Run 


\subsection{Identify the characteristics parameter for urban and rural areas.}

PCA was determined to evaluate sufficient components with an eigenvalue greater than 1 (eigenvalue $>1.0$ ) before the main analysis. The second PCA was used to indicate the parameter with a load factor that is greater than or equal to the value of the 0.6 variance value parameter that was identified for the first PCA. It can be seen from figure 1 that for both PCA listed only one component as the most crucial because of its higher eigenvalues (>1). Further analyses of varimax rotation were done utilizing both areas to identify the characteristics parameter.

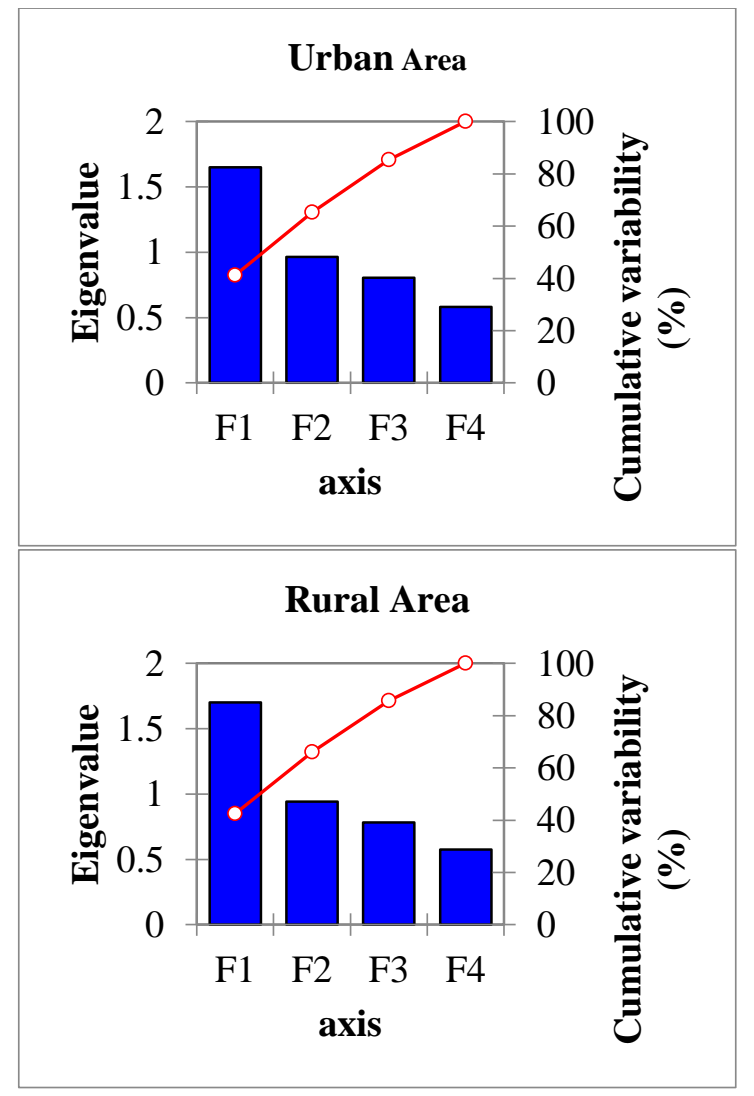

Figure 1. Scree plot of descriptive eigenvalue for urbanrural areas

The PCA pattern is shown in Table 2 after the varimax rotation for both areas. From the table, for the child in an urban area there three components show strong factor loading where the factor loading is greater than 0.6 , which the power by 0.797 is a strong positive factor, coordination by 0.611 and speed with strong negative factors by -0.718 . Similar to the rural area where the factor loading is greater than 0.6 , the speed with a strong positive factor by 0.7346 . For power by -0.7904 and coordination by -0.6245 show that strong negative factor loadings.
Table 2. Factor loading pattern after Varimax rotation (factor loading set at $>0.6$ )

\begin{tabular}{lcccc}
\hline & \multicolumn{2}{c}{ Urban } & \multicolumn{2}{c}{ Rural } \\
\cline { 2 - 5 } & PCA 1 & PCA 2 & PCA 1 & PCA 2 \\
\hline Power (cm) & 0.80 & 0.80 & -0.79 & 0.79 \\
Flexibility (cm) & 0.35 & 0.35 & -0.38 & 0.38 \\
Coordination (no) & 0.611 & 0.611 & -0.62 & 0.62 \\
Speed (sec) & -0.72 & -0.72 & 0.73 & -0.73 \\
Eigenvalue & 1.65 & 1.65 & 1.70 & 1.70 \\
Variability (\%) & 41.24 & 41.24 & 42.54 & 42.54 \\
Cumulative \% & 41.24 & 41.24 & 42.54 & 42.54 \\
\hline
\end{tabular}

Table 3 shows the contribution of the variables after varimax rotation. The contribution for power is $38.49 \%$, flexibility is $7.62 \%$, coordination is $22.63 \%$, and speed is $31.26 \%$. And for the rural area, the contribution for power is $36.72 \%$, flexibility is $8.65 \%$, coordination is $22.92 \%$, and speed is $31.71 \%$. This means that the dominant factor comes from the component power, coordination, and speed for both areas.

Table 3. Contribution of the variables (\%) after varimax

\begin{tabular}{lcc}
\multicolumn{3}{c}{ rotation } \\
\hline & Urban & Rural \\
\hline Power $(\mathrm{cm})$ & 38.49 & 36.72 \\
Flexibility (cm) & 7.62 & 8.65 \\
Coordination (no) & 22.63 & 22.92 \\
Speed (sec) & 31.26 & 31.71 \\
\hline
\end{tabular}

\subsection{Differentiate the effect of residential areas on the physical activity}

Multivariate Analysis of Variance (MANOVA) was carried out across variables (power, flexibility, coordination, and speed and groups of residential areas (urban and rural) to explore the existence of comparison of residential areas group among studied samples with physical fitness performance. Each $\mathrm{F}$ tests the multivariate effect of Residential. These tests are based on the linearly independent pairwise comparisons among the estimated marginal means. The results have been shown in table 4 . The results of the Pillai's Trace multivariate test show that there is a significant effect of significant residential variables $[\mathrm{F}(4,66476)=121.879, \mathrm{p}<.05]$. This means that overall there is a significant difference between urban and rural test data on dependent variables.

Table 4. Multivariate Test

\begin{tabular}{lccccc}
\hline & \multicolumn{3}{c}{ Hypothesis } \\
& Value & $\mathrm{F}$ & $\mathrm{df}$ & Error df & Sig. \\
\hline Pillai's trace & .007 & $121.879 \mathrm{a}$ & 4.000 & 66476.000 & .000 \\
$\begin{array}{l}\text { Wilks' } \\
\text { lambda }\end{array}$ & .993 & $121.879 \mathrm{a}$ & 4.000 & 66476.000 & .000 \\
$\begin{array}{l}\text { Hotelling's } \\
\text { trace }\end{array}$ & .007 & $121.879 \mathrm{a}$ & 4.000 & 66476.000 & .000 \\
$\begin{array}{l}\text { Roy's largest } \\
\text { root }\end{array}$ & .007 & $121.879 \mathrm{a}$ & 4.000 & 66476.000 & .000 \\
\hline
\end{tabular}


Each $\mathrm{F}$ tests the multivariate effect of Residential. These tests are based on the linearly independent pairwise comparisons among the estimated marginal means.

\section{a. Exact statistic}

Table 5 shows the result of Univariate Test. The results of this univariate test show that there is a significant effect of independent variables (residential groups) on the four dependent variables where are power $[\mathrm{F}(1,66479)=$ 203.463, $\mathrm{p}<.05]$, flexibility $[\mathrm{F}(1,66479)=200.173, \mathrm{p}<$ $.05]$, coordination $[\mathrm{F}(1,66479)=152.268, \mathrm{p}<.05]$ and speed $[\mathrm{F}(1,66479)=217.066, \mathrm{p}<.05]$. This means that significantly, urban and rural areas have an effect on the physical activity of children aged 7 .

The results of pairwise comparisons are shown in table 6 . This table shows the results of different means between 2 groups of residential, urban, and rural-based on each physical fitness test. For power, the mean difference between urban and rural is -2.034 . The mean difference for flexibility is -0.543 ; coordination is -0.264 , and speed is 0.072 .

Based on estimated marginal means

*. The mean difference is significant at the .05 level.

b. Adjustment for multiple comparisons: Bonferroni.

The results of the mean for both groups, urban and ruralbased on each physical fitness test, are shown in table 7 . The table has been shown that for the power test, the mean for the rural area is higher than the urban area (102.374>100.340). The same goes for flexibility (26.959>26.416), coordination $(5.427>5.163)$. And for the speed test, the child in the rural area is faster than the urban area $(4.960<5.032)$. This table has shown that children who stay in a rural area are more active than the child stays in an urban area.

Table 5. Univariate Test

\begin{tabular}{llccccc}
\hline Dependent Variable & & Sum of Squares & df & Mean Square & F & Sig. \\
\hline Power & Contrast & 68672.234 & 1 & 68672.234 & 203.463 & .000 \\
& Error & 22437800.133 & 66479 & 337.517 & & \\
Flexibility & Contrast & 4895.647 & 1 & 4895.647 & 200.173 & .000 \\
& Error & 1625885.596 & 66479 & 24.457 & & \\
Coordination & Contrast & 1156.418 & 1 & 1156.418 & 152.268 & .000 \\
& Error & 504882.401 & 66479 & 7.595 & & .000 \\
Speed & Contrast & 86.110 & 1 & 86.110 & 217.066 \\
& Error & 26372.128 & 66479 & .397 & & .000 \\
\hline
\end{tabular}

The $\mathrm{F}$ tests the effect of Residential. This test is based on the linearly independent pairwise comparisons among the estimated marginal means.

Table 6. Pairwise Comparisons

\begin{tabular}{lllrrrrr}
\hline $\begin{array}{l}\text { Dependent } \\
\text { Variable }\end{array}$ & $\begin{array}{l}\text { (I) } \\
\text { Residential }\end{array}$ & $\begin{array}{l}(\mathrm{J}) \\
\text { Residential }\end{array}$ & $\begin{array}{c}\text { Mean } \\
\text { Difference } \\
(\mathrm{I}-\mathrm{J})\end{array}$ & $\begin{array}{c}\text { Std. } \\
\text { Error }\end{array}$ & Sig.b & \multicolumn{2}{c}{$\begin{array}{c}\text { 95\% Confidence Interval for } \\
\text { Differenceb }\end{array}$} \\
\hline Power & Rural & Urban & $2.034^{*}$ & .143 & .000 & 1.755 & Unper Bound \\
Flexibility & Rural & Urban & $.543^{*}$ & .038 & .000 & .468 & .618 \\
Coordination & Rural & Urban & $.264^{*}$ & .021 & .000 & .222 & .306 \\
Speed & Rural & Urban & $-.072^{*}$ & .005 & .000 & -.082 & -.062 \\
\hline
\end{tabular}

Table 7. Estimates Mean

\begin{tabular}{cccccc}
\hline \multirow{2}{*}{$\begin{array}{c}\text { Dependent } \\
\text { Variable }\end{array}$} & Residential & Mean & Std. Error & \multicolumn{2}{c}{$95 \%$ Confidence Interval } \\
\cline { 5 - 6 } Power & Urban & 100.340 & .099 & 100.146 & Lower Bound \\
& Rural & 102.374 & .103 & 102.173 & Upper Bound \\
\hline \multirow{2}{*}{ Flexibility } & Urban & 26.416 & .027 & 26.363 & 102.575 \\
& Rural & 26.959 & .028 & 26.905 & 26.468 \\
Coordination & Urban & 5.163 & .015 & 5.134 & 27.013 \\
\multirow{2}{*}{ Speed } & Rural & 5.427 & .015 & 5.397 & 5.192 \\
& Urban & 5.032 & .003 & 5.025 & 5.457 \\
& Rural & 4.960 & .004 & 4.953 & 4.967 \\
\hline
\end{tabular}


Line graph form for power, flexibility, coordination, and speed for urban and rural groups have been shown in figure 2. From the graph, the line of power, flexibility, coordination counts higher on the right (rural) than left (urban). And for the line of speed shown a decline from left (urban) to the right (rural). This figure has shown that children in rural areas are more active in physical activity than children in urban areas.

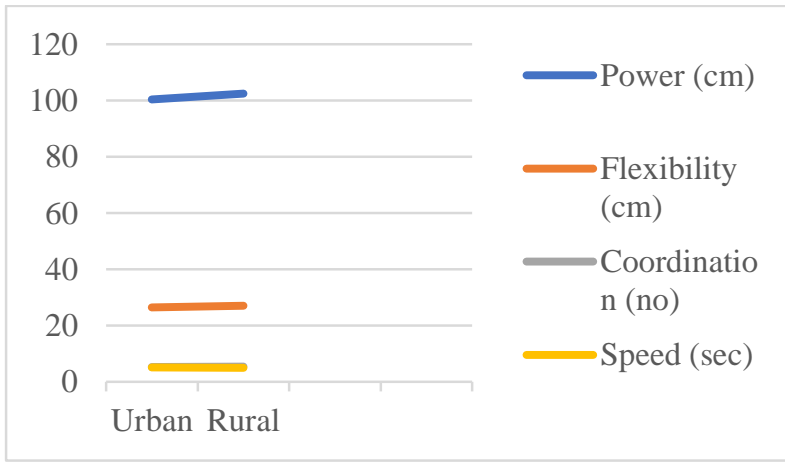

Figure 2. Line graph for mean difference for urban and rural groups

\section{DISCUSSION}

Based on the findings above, the researcher found that the findings have answered the research questions that are what are the characteristics of differences between urban and rural-based on the components of physical fitness test of 7-year-old children in Malaysia and what are the comparison of the effects residential area on the physical fitness test of 7-year-olds in Malaysia. To achieve these objectives, data analysis such as Principal Component Analysis (PCA) and Multivariate Analysis of Variance (MANOVA) was conducted.

PCA results show that both urban and rural have the same characteristics of power, coordination, and speed. Roughly speaking, this indicates that there is no difference in the effect of the residential area on the components of a child's physical fitness test. However, the MANOVA test was performed to answer the question of what is the comparison of the effect of the residential area on the physical fitness test of the child. The results of MANOVA declare that children from rural areas are better than urban areas; although the mean difference shown is not large, it is very significant.

From these results, the main factors that contribute to rural children are better than urban children are more active in physical activity that contributes to the result of the physical fitness test. The latest findings have found that environmental factors, lifestyles, diets, family structures, and cultural differences are directly associated with personal fitness and physical activity [15]. This is also supported by previous study, stating the lack of space adjacent to the home environment limits children's playtime outside the home and thus their level of activity
[16]. In addition, environmental safety factors also encourage parents to allow their children to play in the area [17]. Also reported lifestyle factors contributing to physical inactivity among urban children. Urban children have a propensity to spend a lot of leisure time with an inactive routine such as reading, playing video games, or watching television [18-21]. Children who have employed parents squander their time at home and circumvent playing outside after alma mater. Reported unhealthy food intake also leads to overweight or obesity in children. About $66 \%$ of children in urban areas and $64.3 \%$ of children from rural areas in Selangor reported consuming fast food once in two weeks [22]. This shows that children nowadays, regardless of residential area factors, have been exposed to an unhealthy eating culture. Overweight children often have high blood pressure and high cholesterol and tend to be overweight adults [23,24]. Previous studies have also explained that parents of children's lifespan in inner-city and countryside areas do not include the habit of exercising [15]. This study has explained that children's livelihoods in urban areas occupy most of their time at home since they have fewer chances to involve outdoor. At the same time, children living in rural areas are given the opportunity to play comfortably outside.

\section{CONCLUSION}

Due to the results of the present study, it is apparent that children living in urban areas are less interested in physical activity than children living in rural Malaysia. This problem is compounded by reports that current children in Malaysia are the top five obese in ASEAN [25]. This study may be an essential reminder for parents and other stakeholders to respond with a serious issue. Physical activity reduces critical diseases such as cardiovascular problem, diabetes, and cancer and expands the strength and endurance of the musculoskeletal system, which enhances posture and motor skills [26]-[29]. As a result, it is clear that urban children in Malaysia consume an unhealthy lifestyle. However, it is recommended that training should be given, starting from infancy to achieve a good level of physical fitness. Physical education teachers and health workers in schools, as well as parents, play an important role in this issue [30]. Proper planning and implementing health promotion programs, encouraging regular physical activity practice, need to be implemented to fight against sedentary behavior.

\section{ACKNOWLEDGMENT}

The University of Sultan Zainal Abidin (UniSZA) cooperated with The National Sports Institute (ISN) and the Terengganu State Sports Council (MSNT) are required to collect data on the physical fitness of children. Researchers sincerely thank parents, guardians, school 
authorities and participants for their successful participation in this study.

\section{REFERENCES}

[1] M. I. Goran, M. S. Treuth. Energy expenditure, physical activity, and obesity in children. Pediatric Clinics of North America, 48 (4) (2001) 931-953. DOI: https://doi.org/10.1016/S0031-3955(05)70349-7

[2] Y. Netz, M. J. Wu, N. J. Becker, G. Tenenbaum. Physical activity and psychological well-being in advanced age: a meta-analysis of intervention studies .Psychology and aging, 20 (2) (2005) 272. DOI: https:// doi.org/10.1037/0882-7974.20.2.272

[3] B. K. Sovacool, D. J. Hess. Ordering theories: Typologies and conceptual frameworks for sociotechnical change. Social studies of science, 47 (5) (2017) 703-750. DOI: https://doi.org/10.1177/0306312 717709363

[4] S. Macintyre, L. Macdonald, A. Ellaway. Do poorer people have poorer access to local resources and facilities? The distribution of local resources by area deprivation in Glasgow, Scotland. Social science \& medicine, 67 (6) (2008) 900-914. DOI: https://doi.org/ 10.1016/j.socscimed.2008.05.029

[5] J. Kruk. Lifetime occupational physical activity and the risk of breast cancer: a case-control study. Asian Pac J Cancer Prev, 10 (3) (2009) 443-448.

[6] T. Cai Lian, G. Bonn, Y. Si Han, Y. Chin Choo, W. Chee Piau. Physical activity and its correlates among adults in Malaysia: a cross-sectional descriptive study. PloS one, 11 (6) (2016) e0157730. DOI: https:// doi.org/10.1371/journal.pone.0157730

[7] R. Schwarzer, D. S. Cao, S. Lippke. Stage-matched minimal interventions to enhance physical activity in Chinese adolescents. Journal of Adolescent Health, 47 (6) (2010) 533-539. DOI: https://doi.org/10.1016/j.Jad ohealth.2010.03.015

[8] P. Chillón, F. B. Ortega, J. A. Ferrando, J. A. Casajus. Physical fitness in rural and urban children and adolescents from Spain. Journal of Science and Medicine in Sport, 14 (5) (2011) 417-423. DOI: https:// doi.org/10.1016/j.jsams.2011.04.004
[9] T. Olds, M. Wake, G. Patton, K. Ridley, E. Waters, J. Williams, K. Hesketh. How do school-day activity patterns differ with age and gender across adolescence?. Journal of adolescent health, 44 (1) (2009) 64-72. DOI: https://doi.org/10.1016/j.jadohealth. 2008.05.003

[10] R. R. Joens-Matre, G. J. Welk, M. A. Calabro, D. W. Russell, E. Nicklay, L. D. Hensley. Rural-urban differences in physical activity, physical fitness, and overweight prevalence of children. The Journal of rural health, 24 (1) (2008) 49-54. DOI: https://doi.org/10.111 $1 / \mathrm{j} .1748-0361.2008 .00136 . x$

[11] N. I. Yusoff, M. R. Abdullah, H. Juahir, J. L. F. Lee, S. M. Mat-Rasid, N. A. Kosni, M. K. Zawi. The effect of residence area on motor skill development among children. Indian J. Public Health Res. Dev, 10 (3) (2019) 614-618. DOI: 10.5958/0976-5506.2019.00 569.2

[12] V. K. Matsudo, R. E. Rivet, M. H. Pereira. Standard score assessment on physique and performance of Brazilian athletes in a six tiered competitive sports model. Journal of sports sciences, 5 (1) (1987) 49-53. DOI: https://doi.org/10.1080/0264041 8708729763

[13] M. Karunanithy, G. Prabhavathi, A. H. Beevi, B. H. Ibraheem, K. Kaviyarasu, S. Nivetha, M. Jayachandran. Nanostructured metal tellurides and their heterostructures for thermoelectric applications-a Review. Journal of nanoscience and nanotechnology ,18 (10) (2018) 6680-6707. DOI: https://doi.org/10.116 6/jnn.2018.15731

[14] B. G. Tabachnick, L. S. Fidell, J. B. Ullman. Using multivariate statistics (Vol. 5, pp. 481-498). Boston, MA: Pearson.2007.

[15] M. Özdirenç, A. Özcan, F. Akin, N. Gelecek. Physical fitness in rural children compared with urban children in Turkey. Pediatrics international, 47 (1) (2005) 26-31. DOI : https://doi.org/10.1111/j.1442-200 x.2004.02008.x

[16] D. P. Johns, A. S. Ha. Home and recess physical activity of Hong Kong children. Research quarterly for exercise and sport, 70 (3) (1999) 319-323. DOI: https://doi.org/10.1080/02701367.1999.10608051 
[17] J. F. Sallis, T. L. McKenzie, J. P. Elder, S. L. Broyles, P. R. Nader. Factors parents use in selecting play spaces for young children. Archives of pediatrics $\&$ adolescent medicine, 151 (4) (1997) 414-417. DOI: https://doi.org/10.1001/archpedi.1997.02170410088012

[18] M. S. Faith, N. Berman, M. Heo, A. Pietrobelli, D. Gallagher, L. H. Epstein, D. B. Allison. Effects of contingent television on physical activity and television viewing in obese children. Pediatrics, 107 (5) (2001) 1043-1048. DOI: https://doi.org/10.1542/peds.107.5.1 043

[19] A. Grund, H. Krause, M. Siewers, H. Rieckert, M. J. Müller. Is TV viewing an index of physical activity and fitness in overweight and normal weight children?. Public health nutrition, 4 (6) (2001) 12451251 .

[20] T. G. Lohman, B. Caballero, J. H. Himes, S. Hunsberger, R. Reid, D. Stewart, B. Skipper. Body composition assessment in American Indian children .The American journal of clinical nutrition, 69 (4) (1999) 764S-766S. DOI: https://doi.org/10.1093/ajcn/ 69.4.764S

[21] S. Wilcox, C. Castro, A. C. King, R. Housemann, R. C. Brownson. Determinants of leisure time physical activity in rural compared with urban older and ethnically diverse women in the United States. Journal of Epidemiology \& Community Health, 54 (9) (2000) 667-672. DOI: http://dx.doi.org/10.1136/jech.54.9.667

[22] P. Alam. Nutritional status and eating practices among children aged 4-6 years old in selected urban and rural kindergarten in Selangor, Malaysia. Asian J. Clin. Nutr, 4 (2012) 116-131.

[23] W. R. Clarke, R. M. Lauer. Does childhood obesity track into adulthood?. Critical reviews in food science and nutrition, 33 (4-5) (1993) 423-430. DOI: https://doi .org/10.1080/10408399309527641

[24] P. H. Davis, J. D. Dawson, W. A. Riley, R. M. Lauer. Carotid intimal-medial thickness is related to cardiovascular risk factors measured from childhood through middle age: The Muscatine Study .Circulation, 104 (23) (2001) 2815-2819. DOI: https:// doi.org/10.1161/hc4601.099486
[25] S. Chitturi, G. C. Farrell, J. George. Non alcoholic steatohepatitis in the Asia-Pacific region: Future shock?. Journal of gastroenterology and hepatology, 19 (4) (2004) 368-374. DOI : https://doi.org/10.1111/j.144 0-1746.2003.03252.x

[26] M. L. Booth, A. D. Okely, T. Chey, A. Bauman. The reliability and validity of the physical activity questions in the WHO health behaviour in schoolchildren (HBSC) survey: a population study .British journal of sports medicine, 35 (4) (2001) 263 267. DOI: http://dx.doi.org/10.1136/bjsm.35.4.263

[27] R. V. Luepker, S. B. Johnson, L. Breslow, A. V. Chobanian, C. E. Davis, B. R. Duling, R. L. Washington. Physical activity and cardiovascular health. Journal of the American Medical Association ,276 (3) (1996) 241-246.

[28] L. Millar, P. Kremer, A. de Silva-Sanigorski, M. P. McCabe, H. Mavoa, M. Moodie, B. A. Swinburn. Reduction in overweight and obesity from a 3-year community-based intervention in Australia: the 'It's Your Move!'project. obesity reviews, 12 (2011) 20-28. DOI : https://doi.org/10.1111/j.1467-789X.2011.00904 .X

[29] S. E. Taylor, R. L. Repetti, T. Seeman. Health psychology: what is an unhealthy environment and how does it get under the skin?. Annual review of psychology, 48 (1) (1997) 411-447. DOI: https://doi.org /10.1146/annurev.psych.48.1.411

[30] A. B. H. M. Maliki, M. R. Abdullah, A. Nadzmi, M. A. R. Zainoddin, I. M. Puspitasari, N. F. A. Jibril, S. K. S. Ali. Kids motor performances datasets. Data in brief, 34 (2021) 106582. DOI: https://doi.org/10.1016/j. dib.2020.106582 